\title{
Observações sobre os Cursos de Pós-Graduação na Faculdade de Direito da USP.
}

\author{
Henny Goulart \\ Livre Docente de Direito Penal na Faculdade \\ de Direito da Universidade de São Paulo.
}

Os cursos de Pós- graduação, regulamentados pelo Estatuto da Universidade de São Paulo e seu Regimento Geral e pelas Portarias ns. 885, de 25.8.1969, 1.211, de 25.6.1970, 1.538, de 19.7.1971, surgiram em decorrência do estudo altamente valioso consubstanciado no Parecer $n$. 977, de 1965, elaborado pelos eminentes membros do Conselho Federal de Educação, cujo texto analisa profundamente a origem, necessidade, conceito e características dos Cursos em questão.

Em resumo, o referido parecer mostra que a Pós-Graduação

a) "tem sua origem próxima na estrutura da universidade norte-americana, embora seu desenvolvimento sistemático possa ser considerado como produto da influência germânica";

b) "que o sistema dos Cursos de Pós-Graduação impõe-se hoje em todos os países "como conseqüência natural do extraordinário progresso do saber em todos os setores, tornando impossível proporcionar tratamento completo e adequado para muitas carreiras nos limites dos cursos de graduação";

c) "conceituando tais estudos como "o ciclo de cursos regulares em seguimento à graduação, sistematicamente organizados, visando desenvolver e aprofundar a formação adquirida no âmbito da graduação e conduzindo à obtenção de grau acadêmico"; 
d) e fixando, como características, entre outras, o escalonamento da Pós-Graduação em dois niveis, mestrado e doutorado; o mínimo de um ano para o mestrado e de dois anos para o doutorado; programa de estudos compreendendo um elenco variado de matérias; flexibilidade desse programa; assistência e orientação de um diretor de estudos; rigorosa seleção intelectual dos candidatos etc.

Estabelecido em nossa Faculdade no segundo semestre de 1971, teve continuidade no segundo semestre de 1972, após ter sido reorganizado pelo eminente Professor GofFredo da Silva Telles Junior. Essa reorganização revestiu-se da maior importância, não só pela ordenação dos serviços gerais da secretaria, base indispensável à própria vivência dos Cursos, como pela expedição de numerosas "Instruções", interpretativas daqueles diplomas legais, a fim de que professores e candidatos pudessem ter uma nítida visão do seu valor, conteúdo e desenvolvimento.

Os Cursos de Mestrado e Doutorado se completam quando os respectivos candidatos são aprovados na defesa de suas dissertações ou teses. Esses resultados decorrem da aquisição dos créditos necessários, obtidos mediante freqüência às aulas e seminários, além da produção de trabalhos e provas, indicativos do aproveitamento dos interessados, levando-os até ao exame de qualificação, fase preparatória daquela defesa.

De acôrdo com as referidas "Portarias", cabe ao orientador - denominado diretor de estudos pelo Parecer 977 "fixar e acompanhar o programa de estudos do candidato". E a segunda edição da "Instrução n. 1", elaborada também pelo Coordenador dos nossos Cursos, Professor GoFFredo Telles Junior explicou, em seu item 4) que "todo candidato terá um Docente orientador. Após escolher sua área de concentração, o candidato elegerá o seu orientador, dentre os professores Titulares, Adjuntos e Livre-Docentes dessa mesma área. Caberá ao orientador o programa de estudos 
do candidato, assistir ao candidato em seus cursos e aconselhá-lo na elaboração da sua dissertação de mestrado e da sua tese de doutorado".

Dessa forma, a primeira preocupação do candidato a esses cursos deve ser, necessariamente, a escolha de uma área de concentração de estudos e de um professor orientador.

A Portaria 1.211 , citada, em seu artigo $5 .^{\circ}, \S 1 .^{\circ}$, definiu a área de concentração como sendo "o campo cientifico escolhido pelo candidato, dentro do qual deverá desenvolver as suas atividades de pesquisa, para a elaboração da dissertação ou da tese". Diante dessa definição, dando-se ao candidato inteira liberdade de eleição da área de estudos em que deseja concentrar-se, e do seu orientador, não deveria haver possibilidade de modificação dessa área durante o seu Curso de Mestrado ou Doutorado. Embora com essa mudança tenha o candidato de sujeitar-se à nova seleção - que é feita pelo orientador em relação aos candidatos que se inscrevem na disciplina que ministra - o seu trabalho de pesquisa torna-se-á dispersivo, sem continuidade lógica e, portanto, sem o aproveitamento que poderia ser alcançado se fosse mantida a escolha inicial.

Por outro lado, estabelecendo o referido artigo $5 .^{3}$ que "para cada área de concentração, o Conselho do Departamento definirá as disciplinas obrigatórias e eletivas; entendendo o respectivo $\S 2 .^{\circ}$ por área complementar "o conjunto de outras matérias consideradas necessárias ou convenientes para completar a formação do candidato", e cabendo ao orientador, como vimos, fixar o programa de estudos do candidato, não se deveria deixar totalmente à disposição do candidato eleger as disciplinas dessa área.

É verdade que o mencionado Parecer 977 entendeu que “os processos de aprendizagem se caracterizam pela grande flexibilidade, atribuindo-se aos candidatos larga margem de liberdade na seleção dos cursos"; mas afirmou, também, que devem ser "assistidos e orientados por um diretor de estudos". 
E certo, ainda, que, por ofício de 3 de abril de 1972, a nossa Coordenadoria indagou dos Conselhos dos Departamentos se concordavam em considerar todas as disciplinas dos Cursos de Pós-Graduação como conexas às de cada Departamento, de maneira que o Estudo de qualquer uma pudesse ser tido como complemento cultural do estudo daquelas, pois esse entendimento "além de confirmar a unidade da ciência do Direito, daria ao programa de estudos do Mestrado e Doutorado a grande flexibilidade recomendada pelo Conselho Federal de Educação". E essa anuência foi obtida.

Melhor seria, entretanto, que o Curso fôsse iniciado pela disciplina escolhida em determinada área de concentração e, durante o transcorrer do mesmo, de acôrdo com a dedicação e aplicação do candidato, o orientador fizesse com este o plano de estudos a ser realizado, escolhendo-se as disciplinas complementares, que maior afinidade $e$ interesse representassem em relação à área de concentração eleita, além do tema da dissertação ou tese, a fim de que o interessado iniciasse, desde logo, as pesquisas necessárias e fosse obtendo do professor as indicações e conselhos indispensáveis.

Nos nossos Cursos, o candidato elege, de início, uma ou mais disciplinas em determinada área de concentração e o respectivo professor orientador, e uma ou mais disciplinas complementares em área diversa. Devendo cada orientador ter sob sua responsabilidade apenas vinte candidatos em área de concentração e dando-se preferência, no tocante ao preenchimento das vagas respectivas, aos alunos aprovados no semestre anterior, ocorre que os novos candidatos, menos felizes nas provas de seleção, não aguardam nova oportunidade de matrícula, passando a inscrever-se em áreas de concentração onde exista maior disponibilidade de vagas e elegendo, como disciplinas complementares - para as quais não há seleção -- aquelas em que foram recusados.

Nessas condições, afastam-se muitos candidatos do verdadeiro objetivo dos Cursos, pois passarão, em tese, a se de- 
dicar muito mais às disciplinas complementares do que as das suas áreas de concentração, das quais esperam obter créditos, mas cujos estudos, na verdade, não se interessam aprofundar.

$\mathrm{O}$ orientador, por sua vez, não poderá fixar um programa de estudos para o candidato, assistindo-o e aconselhando-o, pois não contará com o seu real interesse. E ainda que o candidato apresente algum aproveitamento, estudando o mínimo para ser aprovado e obter os crédidos, é evidente que sua atenção não estará voltada para a escolha do tema, nem para as pesquisas, visando a elaboração de dissertação ou tese naquela área de concentração.

Tem ocorrido, também, que alguns candidatos inscrevem-se em mais de uma disciplina da área de concentração. É, sem dúvida, um direito que lhes assiste. Se considerarmos, porém, que os interessados nos Cursos de Pós-Graduação são profissionais atuantes nos mais variados setores, dispondo, na maioria dos casos, de pouquíssimo tempo livre, chegaremos à conclusão de que, salvo raras exceções, não terão oportunidade suficiente para aprofundar seus estudos em várias matériais, concomitantemente.

A solução para esses problemas que já se fazem notar e parecem tomar impulso, desvirtuando as finalidades precípuas dos Cursos de Pós-Graduação, poderia ser, eventualmente, encontrada na adoção de novas medidas que compreendessem:

a) a eleição pelo candidato de uma área de concentração, a que teria de se dedicar especialmente durante o seu curso e que não poderia ser modificada até que completasse o seu Mestrado ou Doutorado;

b) não aceito pelo professor orientador escolhido, quando das provas de seleção, deveria o candidato aguardar nova oportunidades de inscrição, o que implicaria em maior atenção e responsabilidade da sua parte na definição da área de concentração; 
c) escolhido o orientador entre os professores da área de concentração eleita, o candidato, sob a orientação deste, fixaria o seu programa de estudos e pesquisas, com vistas à dissertação ou tese, e escolheria as disciplinas complementares, não ficando excluida a consideração no tocante ao seu interesse ₹ vocação;

d) esgotados um ou dois semestres sem que o candidato tomasse essas providências e demonstrasse, segundo parecer do professor orientador, dedicação e aplicação condizentes com o espírito dos Cursos, seria desligado.

Como se verifica por este roteiro, os candidatos continuariam a ter ampla liberdade na eleição das suas áreas de concentração de estudos; a partir desta definição, entretanto, aceitariam a obrigação correspondente, de estudos aprofundados e pesquisas, consubstanciados em programa fixado e aceito pelos orientadores escolhidos, embora a colaboração daqueles fosse também considerada; de fixação das disciplinas complementares; e da escolha do tema para início do preparo, durante os cursos, da dissertação ou tese, evitando que esse trabalho, que constituem o ponto alto do programa a ser elaborado, sejam totalmente realizados sem orientação, ou com orientação dispersa e indireta, após a obtenção pelos candidatos do número suficiente de créditos.

A elaboração da dissertação ou tese pode, sem dúvida, ser feita após o exame de qualificação, quando os candidatos disponham de mais tempo para meditar e trabałhar. Não há obrigatoriedade, segundo as normas que regem os nossos Cursos, no sentido de que tais trabalhos sejam realizados durante a primeira fase do Pós-Graduação, que é a fase preparatória, das aulas e seminários. 0 certo, porém, é que, levada a afeito na primeira ou na segunda fase do Pós-Graduação, a dissertação ou tese deve ser elaborada sob a orientação efetiva do professor escolhido. 
Nessas condições, tais trabalhos deveriam ser, pelo menos, iniciados, pois se os candidatos programarem e trabalharem suas dissertações ou teses somente no final de seus cursos, não estarão, dai por diante, em contato direto e contínuo com seus respectivos orientadores. Estes, a seu turno, terão aceito novos candidatos, o que se repetirá a cada novo período letivo, aos quais deverão dedicar-se com maior atenção.

Outro ponto favorável a ser obtido com essa orientação seria o melhor equacionamento dos candidatos nas várias áreas complementares - algumas já com número bem elevado - pela efetivação dos mesmos em áreas de real interesse do seu plano de estudos, afastando a possibilidade de, eventualmente, termos de enfrentar problema semelhante ao dos cursos de graduação, que apresentam turmas muito numerosas, onde a dedicação do professor, por maior que seja, não consegue suprir as deficiências do aproveitamento.

Tópico importante a ser também ressaltado é a realização dos seminários, obrigatórios em cada área de concentração, nos quais são levados a efeito os "trabalhos conduzidos".

Na verdade, o ensino, em qualquer grau, vem, cada vez mais, apresentando um caráter acentuadamente técnico e prático. Daí a necessidade dos seminários, com a oportunidade do aluno aprender a trabalhar, debatendo os assuntos, obtendo conclusões e pondo em prática conhecimentos teóricos. Bem realizados, os seminários apresentam a grande vantagem de treinar o espírito numa especialidade, colocando-o, ainda, em contato com as especialidades conexas.

Para bem desempenhar sua alta finalidade, entrelanto, não pode um seminário prescindir de instalações adequadas, como sala própria, convenientemente mobiliada, dotada de publicações e textos legais indispensáveis à atuação do professor e dos seminaristas, embora o ideal fôsse uma biblioteca privativa. A esse problema também deverá 
ser dada atenção especial na continuidade e aperfeiçoamento dos nossos Cursos, pois, embora os nossos Departamentos disponham de boas instalações e bibliotecas especializadas, nem sempre é possível a realização dos seminários em suas dependências, dada a freqüência, para estudos e consultas de livros, dos alunos dos cursos de graduaçâo.

Por todo o exposto, parece da maior necessidade incutir profundamente nos interessados o verdadeiro espírito dos Cursos de Pós-Graduação.

Embora seja norma geral falar-se na formação de docentes como objetivo único desses Cursos, a sua finalidade precípua é a formação de docentes e de pesquisadores nas diversas áreas de estudos a que forem aplicados.

Anteriormente, o Decreto 11.530, de 18 de Março de 1915, que reorganizou o ensino secundário e o superior, estabeleceu em seu artigo 136 que a defesa de tese nas Faculdades de Medicina ou Direito seria facultativa e regulada pelos respectivos Regimentos.

Em seguida, o Decreto $16.782 A$, de 13 de Janeiro de 1925, artigo 60, mandou conferir o título de doutor em Direito ao bacharel em ciências jurídicas e sociais, que fosse aprovado, em defesa de tese, ou em concurso para professor catedrático, ou docente-livre, sem estabelecer a forma como deveria ser realizada essa defesa, o que a tornava variável na conformidade dos regimentos internos das Faculdades de Direito.

Esta situação perdurou até o advento do Decreto 19.852, de 11 de Abril de 1931, que, dispondo sobre o ensino superior no Brasil, tornou possível a realização de "cursos de aperfeiçoamento e de especialização", os quais, segundo o artigo 39, poderiam "ser organizados e realizados pelos professores catedráticos, ou pelos docentes-livres, cabendo ao Conselho Técnico Administrativo autorizar esses Cursos, aprovar os respectivos programas e expedir instruções relativas ao seu funcionamento". Estipulava, ainda, no artigo 90, que "os institutos universitários de que trata o artigo $5 .^{\circ}$, item I (entre eles, a Faculdade de Direito), expedirão 
diplomas de doutor quando, após a conclusão dos cursos normais, técnicos ou científicos, e atendidas outras exigências regulamentares dos respectivos institutos, o candidato defender uma tese de sua autoria", exigindo, no $\S 1 .^{\circ}$ do mesmo artigo, que essa tese constituisse "publicação de real valor sobre assunto de natureza técnica ou puramente científica" e, no $\S 2 .^{\circ}$, que a defesa respectiva seria feita "perante uma comissão examinadora, cujos membros deverão possuir conhecimentos especializados da matéria".

Tratando, porém, da seleção dos professores catedráticos e docentes-livres, não exigia dos candidatos a concursos apresentação do título de doutor (artigos 51, 52 e 75).

A Lei 6.032, de 4 de Abril e respectivo Regimento, aprovado pela Congregação da Faculdade de Direito em 4 de Maio do mesmo ano, regulamentou, posteriormente, o "Curso de Especialização". Em seguida, a Portaria GR 351, de 25 de Abril de 1967 dispôs sobre o Regimento do processo de Doutoramento, estabelecendo o período mínimo de um ano, a contar da inscrição, para apresentação de dissertação ou tese.

Finalmente, a Portaria Gr 432, de 24 de novembro de 1967, reformulou aquele "Curso", fundamentando-o na citada Lei 6.032, fixando sua duração em dois anos e estabelecendo que sua finalidade era "a sistematização filosófica e o desenvolvimento aprofundado dos estudos jurídicos, promovendo, mediante investigações científicas, a formação de técnicos nas diversas especialidades e de professores para a docência universitária".

Atualmente, a referida Portaria 1.211, que aprovou o Regulamento dos Cursos de Pós-Graduação da nossa Faculdade, diz, no artigo $1 .^{\circ}$, que seu objetivo é "a sistematização filosófica e o desenvolvimento aprofundado dos estudos jurídicos, promovendo, mediante investigações científicas, a formação de docentes e de pesquisadores nas diversas areas do Direito". O Professor Goffredo da Silva Telles, na Instrução que fez expedir em Novembro de 1972, expressou-se 
da seguinte forma a respeito: "Os Cursos de Pós-Graduação foram criados para ministrar ensino científico avançado. Objetivam a formação de especialistas abalizados. Visam o adestramento requintado de técnicos. Procuram propiciar o aparecimento de profissionais criadores. Seu fim essencial é preparar pesquisadores docentes, que sejam capazes de fazer da Universidade um grande centro de cultura humana, uma instituição verdadeiramente universitária, onde a qualidade do ensino infunda, no espírito dos que a freqüentam, acendrado amor ao saber".

Em suma, como nos disse o dedicado mestre, os nossos Cursos devem objetivar a formação de "gente", no seu mais alto e relevante sentido, de pessoas de formação científica aprimorada, de espírito de iniciativa, de amor ao estudo, dedicadas ao trabalho que realizam, de seres que possam, realmente, servir bem aos vários setores da comunidade. $\mathrm{E}$ isto não se obtem sem um trabalho metódico, sem um programa orientado e sem real dedicação, quer de professores, quer de candidatos.

Fala-se muito hoje em dia em crise da educação em geral e, principalmente, do preparo universitário. Condena-se, e com razão, o aumento indiscriminado de faculdades sem que, paralelamente, estejam os responsáveis em condições de oferecer aos estudantes, em termos quer de administração, quer de ensino teórico e prático, a suficiente base para que possam tornar-se profissionais competentes. Há cada vez mais, uma procura exigente de cursos de especialização, visando menos o aperfeiçoamento do que sanar, em parte, as lacunas do ensino recebido. Diante disso, programas novos tem sido elaborados e a prática constante dos seminários ativada.

É indispensável, porém, que, o aluno colabore, efetivamente, com o professor, para a real eficiência do seu aprendizado ou do seu aperfeicoamento, animando-se de um desejo sincero de aprender, dedicando-se com empenho à realização das tarefas programadas, entre as quais se des- 
tacam as práticas dos seminários e as pesquisas dirigidas à elaboração dos trabalhos e provas e, especialmente, de uma dissertação ou tese. Acima de tudo, deverá compreender que o professor, embora desempenhe decisivo papel na arte de educar, apresenta-se, nos Cursos de Pós-Graduação, mais que em outros, tão somente como iniciador das renovadas atividades escolares do candidato, como transitório guia que, em pouco tempo, não estará mais ao seu lado, devendo, por isso mesmo, esforçar-se o máximo para, cada vez mais, aprender e enunciar seus conhecimentos sozinho.

Aspectos interessantes a respeito do que comentamos são mostrados no relatório de VANDick L. DA Nóbrega, sobre As Novas Universidades Alemãs, declarando que o objetivo maior das universidades na Europa é a pesquisa, bem como o ensino nela apoiado e a ela vinculado. No tocante às inovações que apresentam, traz a orientação dominante na Alemanha, no sentido de não dedicar-se o professor apenas ao ensino, mas tornar-se, alternada e obrigatoriamente, professor e pesquisador. Por isso, durante um período letivo, o professor ministra cursos, proferindo preleções a executando, ainda, outras atividades peculiares ao ensino; e no período seguinte irá dedicar-se, exclusivamente, à pesquisa. Os temas objetos dessas pesquisas são indicados pelos próprios professores, de acordo com as observações colhidas no período de sua atividade docente. E para que esta seja bem realizada, cada professor não terá mais do que trinta estudantes sob sua orientação.

Dessa forma incentiva-se, sobremaneira, a pesquisa, e também a formação de novos docentes, necessários a cada disciplina, pela redução do número de alunos em cada turma.

Outro ponto que tem sido considerado nas Universidades Alemãs é a criação de setores especializados em cada Instituto, o qual formula programas de pesquisas a serem realizados por comissões, integradas por docentes con- 
vocados nos vários Departamentos. Tais convocações não impedem, nem restringem as funções dos pesquisadores isolados, pois, conforme o tema e a qualidade das pesquisas que estejam a realizar, os resultados obtidos poderão ser incorporados ao trabalho de equipe da comissão.

Por fim, a continuidade desse tipo de trabalho, poderá levar à criação de Centros de Pesquisas, constituído por docentes de diversos Institutos ou setores especializados, com programação de relevo para a ciência e prestação de serviços à comunidade, como vem sendo realizado com inteiro êxito em várias universidades americanas.

Em plano mais genérico, poderiam ser instalados, nos diversos Institutos, cursos de especialização, aperfeiçoamento e extensão universitária, que atenderiam a demanda de numerosos candidatos que reclamam o aprofundamento de conhecimentos em áreas restritas de investigação teórica, ou da atividade profissional; a atualização ou aprimoramento de conhecimentos ou técnicas de trabalho; a difusão de conhecimentos e técnicas de trabalho, para elevar a eficiência técnico-profissional e os padrões culturais da comunidade em geral, respectivamente. Esta conceituação está inserta na "Deliberação" 5-73, aprovada pelo Conselho Estadual de Educação e homologada pela Secretaria da Educação do Estado de São Paulo.

Esperamos, muito firmemente, que todas essas idéias se tornem realidade em breve entre nós. Só poderemos concretizá-las, no entanto, se desde já encaminharmos os nossos Cursos de Pós-Graduação para esses objetivos, se conseguirmos que um número cada vez maior de professores se dediquem, exclusivamente, ao ensino e à pesquisa, ao mesmo tempo em que os Poderes Públicos oferecem às Universidades as condições necessárias à consecução dessas tarefas tão relevantes.

São Paulo, 1/5/1973. 